\title{
Endogenous Serotonin Contributes to a Developmental Decrease in Long-Term Potentiation in the Rat Visual Cortex
}

\author{
Yoshikuni Edagawa, ${ }^{1}$ Hiroshi Saito, ${ }^{1}$ and Kazuho Abe ${ }^{1,2}$ \\ 1Department of Chemical Pharmacology, Faculty of Pharmaceutical Sciences, The University of Tokyo, Tokyo 113-0033, \\ Japan, and 2Department of Pharmacology, School of Pharmacy, Hoshi University, Tokyo 142-8501, Japan
}

The primary visual cortex shows synaptic plasticity during a postnatal "critical period," and its plasticity declines with development. Indeed, we found a developmental decrease in the induction of long-term potentiation (LTP) in the rat visual cortex. In visual cortex slices obtained from 2- to 3-week-old rats, tetanic stimulation $(100 \mathrm{~Hz}$ for $1 \mathrm{sec}$, twice at an interval of 30 $\mathrm{sec}$ ) of the white matter reproducibly induced LTP of field potentials in layer II/III. However, in slices from 5-week-old rats, the same tetanic stimulation failed to induce LTP. We hypothesized that endogenous serotonin $(5-\mathrm{HT})$ is responsible for the developmental decrease in visual cortex LTP, because the induction of visual cortex LTP was suppressed by the addition of exogenous 5-HT (10 $\mu \mathrm{m})$ and because the amount of 5-HT in the visual cortex increased during development. To test this hypothesis, we investigated the effect of methysergide, a 5-HT receptor antagonist, on the induction of visual cortex LTP. When visual cortex slices from 5-week-old rats were perfused with 50 $\mu \mathrm{M}$ methysergide, tetanic stimulation of the white matter induced robust LTP in layer II/III. Furthermore, serotonergic neurons were lesioned by intracerebroventricular injection of 5,7dihydroxytryptamine (5,7-DHT). LTP was induced in visual cortex slices from 5,7-DHT-treated, 5-week-old rats. These results suggest that the induction of visual cortex LTP in 5-week-old rats is suppressed by endogenous 5-HT. 5-HT may be a factor that determines a critical period for synaptic plasticity in the rat visual cortex.

Key words: long-term potentiation; serotonin; visual cortex; postnatal development; field potential; rat
Some synapses in the primary sensory cortex display experiencedependent synaptic plasticity (Wiesel and Hubel, 1963). Synaptic plasticity in the visual cortex appears during a postnatal stage termed "critical period" and then declines with development (Fagiolini et al., 1994; Kirkwood et al., 1995). As a cellular basis of activity-dependent synaptic plasticity, long-term potentiation (LTP) of excitatory synaptic transmission was first demonstrated in the hippocampal formation (Bliss and Lømo, 1973) and has been reported in other brain regions, including the visual cortex (Komatsu et al., 1981; Lee, 1982; Artola and Singer, 1987; Bear et al., 1992). Visual cortex LTP was observed in slices from rats during a postnatal critical period but disappeared thereafter (Perkins and Teyler, 1988; Kato et al., 1991; Kirkwood et al., 1995). These observations support the idea that visual cortex LTP underlies an experience-dependent modulation of visual functions such as the ocular dominance plasticity (Rauschecker, 1991; Daw, 1994). However, it is not fully understood what factor determines the developmental change in visual cortex LTP.

Serotonin [5-hydroxytryptamine (5-HT)] plays many important roles as a neurotransmitter or neuromodulator in the CNS (Smith and Sweet, 1978). Serotonergic neurons are located mainly in the dorsal and medial raphe nuclei and send neural projections to a number of brain regions, including the visual cortex (Papadopoulos et al., 1987; Bennett-Clarke et al., 1991; Koh et al., 1991). The presence of 5-HT receptors in the visual cortex has been demonstrated by radioligand-binding studies (Dyck and Cynader, 1993; Rakic and Lidow, 1995) or in situ hybridization (Wright et al.,

\footnotetext{
Received June 8, 2000; revised Nov. 16, 2000; accepted Dec. 19, 2000.

Correspondence should be addressed to Dr. Kazuho Abe, Department of Pharmacology, School of Pharmacy, Hoshi University, 2-4-41 Ebara, Shinagawa-ku, Tokyo 142-8501, Japan. E-mail: abe@hoshi.ac.jp.

Copyright (C) 2001 Society for Neuroscience $0270-6474 / 01 / 211532-06 \$ 15.00 / 0$
}

1995), indicating that 5-HT functions in the visual cortex. It has been proposed that 5-HT plays an important role in the formation of cortical columns ( $\mathrm{Gu}$ and Singer, 1995). In addition, we have found recently that 5-HT inhibits the induction of the LTP of layer II/III field potentials evoked by stimulation of layer IV in rat visual cortex slices (Edagawa et al., 1998a,b, 1999, 2000). Furthermore, it has been reported that the distribution and density of serotonergic fibers in the visual cortex are changed during postnatal development (Foote and Morrison, 1984; Nakazawa et al., 1992; Doli et al., 1996). Therefore, we hypothesized that 5-HT is responsible for the developmental decrease in visual cortex LTP. To test this hypothesis, we investigated in this study the effect of 5-HT, 5-HT receptor antagonists, or serotonergic depletion on the induction of LTP in visual cortex slices obtained from different ages of postnatal rats.

\section{MATERIALS AND METHODS}

Animals. Male Wistar rats (2-5 weeks old; Nihon SLC, Shizuoka, Japan) were maintained and raised under standard conditions $\left(23 \pm 1^{\circ} \mathrm{C} ; 12 \mathrm{hr}\right.$ light/dark cycle; food and water ad libitum). All efforts were made for the care and use of animals according to the Guideline for Animal Experiment of the Faculty of Pharmaceutical Sciences, the University of Tokyo.

Chemicals. 5-HT creatinine sulfate, 5,7-dihydroxytryptamine (5,7DHT), and NAN-190 were purchased from Sigma (St. Louis, MO). 6-Cyano-7-nitroquinoxaline-2,3-dione (CNQX), methysergide maleate, and mesulergine were purchased from Research Biochemicals (Natick, MA). Other chemicals were purchased from Wako Pure Chemicals (Osaka, Japan).

Slice preparation and field potential recording. Visual cortex slices were prepared from 2- to 5-week-old rats as previously described (Edagawa et al., 1998a). Briefly, whole brain was quickly isolated and placed in ice-cold artificial CSF (ACSF) consisting of (in mM): $124 \mathrm{NaCl}, 5 \mathrm{KCl}$, $1.2 \mathrm{KH}_{2} \mathrm{PO}_{4}, 1.3 \mathrm{MgSO}_{4}, 2.4 \mathrm{CaCl}_{2}, 26 \mathrm{NaHCO}_{3}, 10$ glucose, bubbled with $95 \% \mathrm{O}_{2} / 5 \% \mathrm{CO}_{2}$. The brain was trimmed to an occipital brain block containing the primary visual cortex and then cut into $400-\mu \mathrm{m}$-thick coronal slices with a Vibratome (DTK-1500; Dosaka, Kyoto, Japan). The 
slices were allowed to recover for $>40 \mathrm{~min}$ in an incubation chamber containing ACSF that was oxygenated $\left(95 \% \quad \mathrm{O}_{2} / 5 \% \quad \mathrm{CO}_{2}\right)$ and maintained at $34^{\circ} \mathrm{C}$. Each slice was transferred into a recording chamber $(2$ $\mathrm{ml})$ in which it was continuously perfused with warmed $\left(34^{\circ} \mathrm{C}\right)$ and oxygenated $\left(95 \% \quad \mathrm{O}_{2} / 5 \% \quad \mathrm{CO}_{2}\right)$ ACSF at a flow rate of $2 \mathrm{ml} / \mathrm{min}$. As shown in Figure $1 A$, a bipolar tungsten electrode was placed on the white matter or layer IV, and single-pulse test stimulation (0.05 msec duration) was applied at intervals of $30 \mathrm{sec}$. The evoked potentials were extracellularly recorded from layer II/III with a glass capillary microelectrode filled with $0.9 \% \mathrm{NaCl}$ (tip resistance, 2-3 M 2 ). The stimulus intensity was set to evoke a synaptic potential of $\sim 50 \%$ of the maximum amplitude. To induce potentiation of evoked synaptic potentials, tetanic stimulation $(100 \mathrm{~Hz}$ for $1 \mathrm{sec}$, twice at an interval of $30 \mathrm{sec}$ ) was applied at the same intensity through the same electrode as that used for test stimulation. Drugs were delivered by perfusion.

Intracerebroventricular injection. Rats (27-d-old) were anesthetized with an intraperitoneal injection of sodium pentobarbital $(50 \mathrm{mg} / \mathrm{kg})$ and fixed in a stereotaxic apparatus. A stainless steel cylindrical cannula (outer diameter, $0.9 \mathrm{~mm}$; length, $15 \mathrm{~mm}$ ) was implanted in each animal so that the tip of the cannula was set in the left lateral ventricle $(1.5 \mathrm{~mm}$ lateral to the midline, $0.8 \mathrm{~mm}$ posterior to the bregma, $3.5 \mathrm{~mm}$ ventral to the skull surface). The implanted cannulas were fixed with dental cement. These cannulas served as guide cannulas for intracerebroventricular injection. The operated rats were allowed to recover for $6 \mathrm{~d}$. All rats were housed individually with food and water available ad libitum. 5,7-DHT was dissolved in saline containing $0.1 \%$ ascorbic acid and injected into the brain through the implanted guide cannula. An injection cannula connected to a micrometer syringe was very gently inserted into the guide cannulas, and $10 \mu \mathrm{l}$ of 5,7 -DHT solution $(5 \mu \mathrm{g} / \mu \mathrm{l})$ or the vehicle (saline containing $0.1 \%$ ascorbic acid) was injected over a period of $3 \mathrm{~min}$. The rats were allowed to recover for $6 \mathrm{~d}$ before the experiments.

Determination of 5-HT concentration. Whole brain was isolated and placed in ice-cold PBS, pH 7.4. The visual cortex region was dissected and transferred in $1 \mathrm{ml}$ of $0.1 \mathrm{M}$ perchloric acid. The tissue was homogenized and centrifuged at $15,000 \times g$ for $15 \mathrm{~min}$ at $4^{\circ} \mathrm{C}$. The supernatant was subjected to analysis with HPLC with an electrochemical detection system (BAS, Tokyo, Japan). The mobile phase consisted of $50 \mathrm{~mm}$ tartaric acid, $40 \mathrm{~mm}$ sodium acetate, $0.5 \mathrm{~mm}$ disodium ethylenediaminetetraacetate, $650 \mu \mathrm{M}$ sodium 1-octane sulfonate, and $5 \%(\mathrm{v} / \mathrm{v})$ acetonitrile, $\mathrm{pH}$ 3.2. 5-HT was identified by retention time and quantitated by peak area. The concentration of 5-HT in samples was estimated from the standard curve constructed with known concentrations of 5-HT.

\section{RESULTS}

\section{Developmental change in visual cortex LTP}

It has been reported previously that a developmental decrease in the ability to exhibit LTP is observed in the white matter-layer II/III pathway of the visual cortex slices obtained from 3- to 5-week-old rats (Perkins and Teyler, 1988; Kato et al., 1991; Kirkwood et al., 1995). Therefore, we first investigated the induction of LTP in the white matter-layer II/III pathway of rat visual cortex. As shown in Figure $1 B$, single-pulse test stimulation of the white matter evoked a negative-going field potential in layer II/III. There was no difference among 2- to 5-week-old rats in the waveform of field potentials (Fig. 1B) or in the size of maximal field potentials (Table 1). In any of the 2- to 5-week-old rats, the evoked potential was completely abolished by removing extracellular $\mathrm{Ca}^{2+}$ or by adding the non-NMDA receptor antagonist CNQX ( $n=5$; data not shown), indicating that it represents non-NMDA receptor-mediated excitatory synaptic potentials. In the slices obtained from 3-week-old rats, application of tetanic stimulation $(100 \mathrm{~Hz}$ for $1 \mathrm{sec}$, twice at an interval of $30 \mathrm{sec}$ ) produced robust LTP of excitatory synaptic potentials (Fig. 1C). The LTP developed slowly, reached a maximum $\sim 15-20 \mathrm{~min}$ after tetanic stimulation, and lasted $>60 \mathrm{~min}$. The slices from 2-week-old rats exhibited LTP, the time course and magnitude of which were virtually the same as those in the slices from 3-weekold rats (Table 1). The slices from 4-week-old rats exhibited LTP, but the magnitude was smaller than that in the slices from

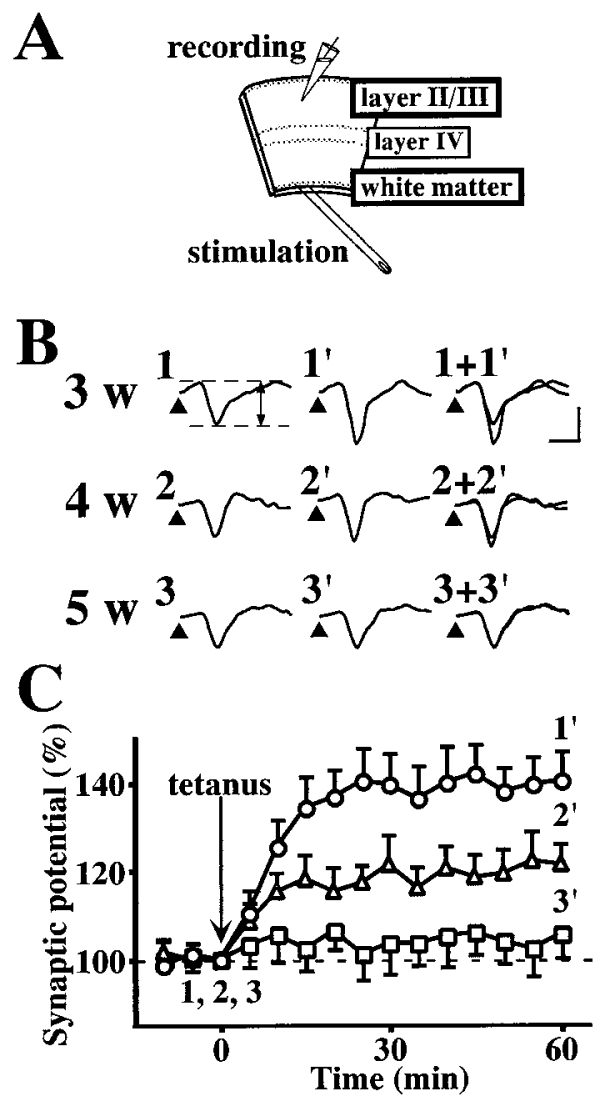

Figure 1. LTP of layer II/III field potentials evoked by stimulation of the white matter in the visual cortex slices obtained from 3- to 5-week-old rats. $A$, Schematic illustration of visual cortex slice showing stimulating and recording sites. $B$, Sample records of layer II/III field potentials evoked by test stimulation of the white matter at the times denoted by the numbers in $C$. Test stimulation was delivered at the times indicated by arrowheads. The amplitude of the negative-going potential was measured as an index of excitatory synaptic transmission. Calibration: vertical, 0.2 $\mathrm{mV}$; horizontal, $5 \mathrm{msec}$. $C$, Time course of LTP in the visual cortex slices obtained from rats that were $3(\bigcirc), 4(\triangle)$, or $5(\square)$ weeks old. Tetanic stimulation $(100 \mathrm{~Hz}$ for $1 \mathrm{sec}$, twice at an interval of $30 \mathrm{sec})$ was applied at time 0 ; the amplitude of excitatory synaptic potential is expressed as a percentage of the baseline value immediately before tetanic stimulation. Data are the means $\pm \operatorname{SEM}(n=5)$.

3-week-old rats (Fig. 1B, C, Table 1). The slices from 5-week-old rats exhibited no LTP (Fig. $1 B, C$, Table 1). Although we attempted to induce LTP by using various conditions of tetanic stimulation, including theta burst stimulation (Kirkwood et al., 1995), LTP was not induced by any conditions of tetanic stimulation in the slices from 5 -week-old rats $(n=5$; data not shown). For comparison, we also investigated the induction of LTP in the layer IV-layer II/III pathway. The size of field potentials and the induction of LTP in this pathway were unchanged among 2- to 5-week-old rats (Table 1). Therefore, the developmental decrease in the ability to exhibit LTP appears to be specific to the white matter-layer II/III pathway.

\section{Possible role of $5-\mathrm{HT}$}

It has been reported that the distribution and density of serotonergic fibers are changed during postnatal development (Foote and Morrison, 1984; Nakazawa et al., 1992; Doli et al., 1996). To the best of our knowledge, however, there are no available data on the content of 5-HT in developing visual cortex. We therefore determined the content of 5-HT in the visual cortex of 3- to 
Table 1. Developmental changes in synaptic plasticity and 5-HT content in the rat visual cortex

\begin{tabular}{|c|c|c|c|c|c|}
\hline \multirow[b]{2}{*}{$\begin{array}{l}\text { Age } \\
\text { (weeks) }\end{array}$} & \multicolumn{2}{|c|}{ White matter-II/III pathway } & \multicolumn{2}{|c|}{ Layer IV-II/III pathway } & \multirow[b]{2}{*}{ 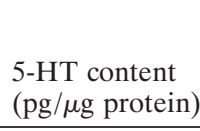 } \\
\hline & $\begin{array}{l}\text { Maximal synaptic } \\
\text { potential }(\mathrm{mV})\end{array}$ & $\operatorname{LTP}(\%)$ & $\begin{array}{l}\text { Maximal synaptic } \\
\text { potential }(\mathrm{mV})\end{array}$ & LTP $(\%)$ & \\
\hline 2 & $0.58 \pm 0.09$ & $139.4 \pm 6.9$ & $0.94 \pm 0.05$ & $140.5 \pm 5.7$ & n.d. \\
\hline 3 & $0.54 \pm 0.05$ & $137.0 \pm 7.4$ & $0.93 \pm 0.10$ & $139.2 \pm 4.2$ & $86.5 \pm 13.8$ \\
\hline 4 & $0.62 \pm 0.11$ & $121.1 \pm 6.7$ & $0.94 \pm 0.10$ & $141.5 \pm 8.2$ & $155.5 \pm 18.4$ \\
\hline 5 & $0.60 \pm 0.04$ & $102.5 \pm 7.3^{* *}$ & $0.89 \pm 0.05$ & $138.9 \pm 7.2$ & $309.9 \pm 30.6 * *$ \\
\hline
\end{tabular}

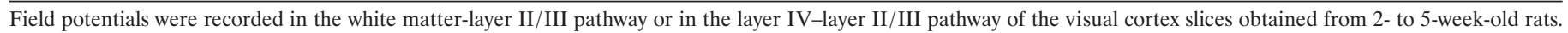

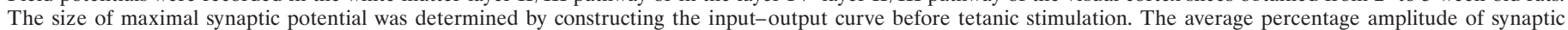

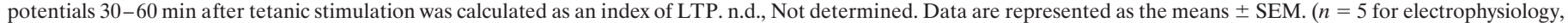
$n=12$ for determination of $5-\mathrm{HT})$. ${ }^{* *} p<0.01$ versus 3 weeks; Tukey's test after ANOVA.

5-week-old rats. As shown in Table 1, the 5-HT content increased with development.

We previously found that 5-HT inhibits the induction of LTP in the layer IV-layer II/III pathway of rat visual cortex slices (Edagawa et al., 1998a). However, the effect of 5-HT on LTP in the white matter-layer II/III pathway remained unknown. Therefore, the effect of exogenously applied 5-HT on the induction of LTP was investigated in the white matter-layer II/III pathway of the slices from 3-week-old rats. Addition of 5-HT $(10 \mu \mathrm{M})$ did not affect the baseline synaptic potential, but significantly inhibited the induction of LTP after tetanic stimulation (Fig. 2A). The inhibitory effect of 5-HT was concentration dependent in the range of $0.1-10 \mu \mathrm{M}$ (Fig. $2 B$ ). To determine whether the effect of 5 -HT is mediated by 5 -HT receptors, the influence of the 5-HT receptor antagonist methysergide was investigated. Methysergide (50 $\mu \mathrm{M})$ alone had no significant effect on LTP in the white matter-layer II/III pathway of the slices from 3-week-old rats. The mean synaptic potential amplitude 30-60 min after tetanic stimulation in the absence and presence of $50 \mu \mathrm{M}$ methysergide was $141.2 \pm 2.7(n=5)$ and $142.2 \pm 7.7(n=4)$, respectively. However, the inhibitory effect of 5-HT was significantly blocked by the presence of methysergide. The mean synaptic potential amplitude 30-60 min after tetanic stimulation in the slices treated with $10 \mu \mathrm{M}$ 5-HT alone and $10 \mu \mathrm{M} 5$-HT plus $50 \mu \mathrm{M}$ methysergide was $104.2 \pm 5.4(n=5)$ and $137.8 \pm 6.1(n=4)$, respectively ( $p<0.05$; Tukey's test).

The above observations raised the possibility that 5-HT increases with development and inhibits the induction of LTP via 5-HT receptors. If this is the case, the impairment of LTP induction observed in slices from 5-week-old rats should be reversed by blocking the 5-HT receptor. Therefore, we investigated the influence of methysergide on the induction of LTP in the slices from 5-week-old rats. Methysergide $(50 \mu \mathrm{M})$ did not affect the baseline synaptic potential before tetanic stimulation. Tetanic stimulation failed to induce LTP in control slices but did induce LTP in the presence of $50 \mu \mathrm{M}$ methysergide (Fig. 3A). The magnitude of LTP induced in the methysergide-treated slices from 5-week-old rats (Fig. 3A, black triangles) was comparable with that in intact slices from 3 -week-old rats (Fig. $2 A$, white circles). Previous studies with autoradiography and in situ hybridization demonstrated that among 5-HT receptor subtypes, $5-\mathrm{HT}_{1 \mathrm{~A}}$ and $5-\mathrm{HT}_{2}$ receptors are highly expressed in the visual cortex (Dyck and Cynader, 1993; Wright et al., 1995). Furthermore, it has been reported that the $5-\mathrm{HT}_{2 \mathrm{C}}$ receptor is involved in 5-HT-induced synaptic modification in the kitten visual cortex (Kojic et al., 1997, 2000). Therefore, we also investigated the influences of the selective $5-\mathrm{HT}_{1 \mathrm{~A}}$ receptor antagonist NAN-190
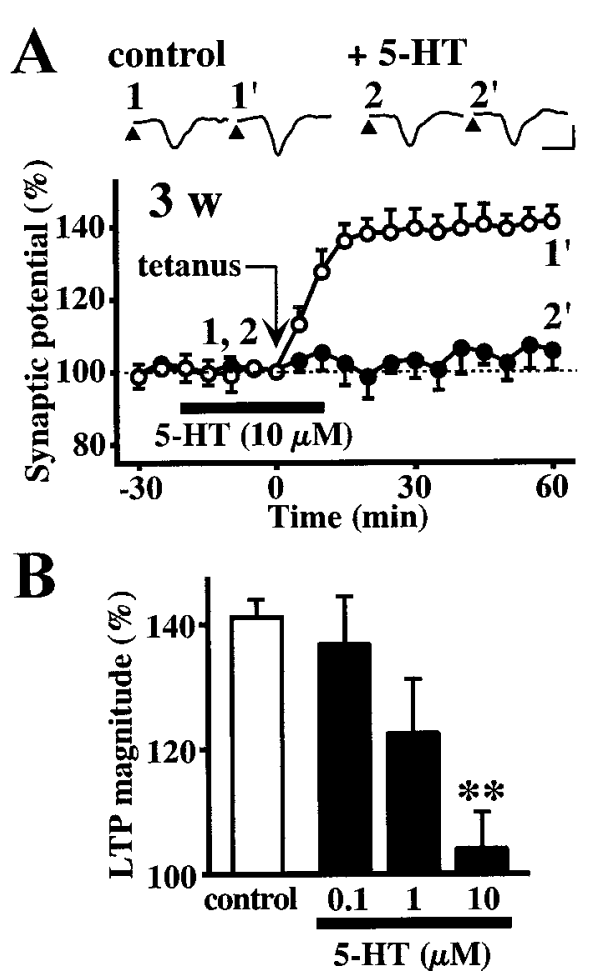

Figure 2. The effect of 5-HT on the induction of LTP in the white matter-layer II/III pathway in the visual cortex slices obtained from 3 -week-old rats. $A$, Time course of LTP. Tetanic stimulation was applied in the absence $(\bigcirc)$ or presence $(O)$ of $10 \mu \mathrm{M}$ 5-HT. 5-HT was added during the time indicated by the horizontal bar ( -20 to $10 \mathrm{~min})$. Insets are sample records at the times denoted by the numbers. Calibration: vertical, $0.3 \mathrm{mV}$; horizontal, $5 \mathrm{msec}$. $B$, Concentration-dependent effect of 5-HT. The average of the percentage amplitude of synaptic potentials 30-60 min after tetanic stimulation was calculated to compare the magnitude of LTP in each group. Data are the means $\pm \operatorname{SEM}(n=5) . * * p<0.01$ versus control group; Tukey's test after ANOVA.

and the selective 5- $\mathrm{HT}_{2 \mathrm{C}}$ receptor antagonist mesulergine on LTP in the slices from 5 -week-old rats. As shown in Figure $3 B$, both NAN-190 $(10-100 \mu \mathrm{M})$ and mesulergine $(0.1-1 \mu \mathrm{M})$ significantly facilitated the induction of LTP in slices from 5 -week-old rats.

To further support the role of 5-HT in the developmental change of LTP, serotonergic neurons were lesioned with 5,7DHT. Four-week-old rats were subjected to intracerebroventricular injection of 5,7-DHT $(5 \mu \mathrm{g} / \mu \mathrm{l}, 10 \mu \mathrm{l})$ or the vehicle (saline containing $0.1 \%$ ascorbic acid) and left for $6 \mathrm{~d}$. The injection of the vehicle did not affect 5 -HT content in the visual cortex slices, whereas 5,7-DHT injection significantly reduced the 5-HT con- 

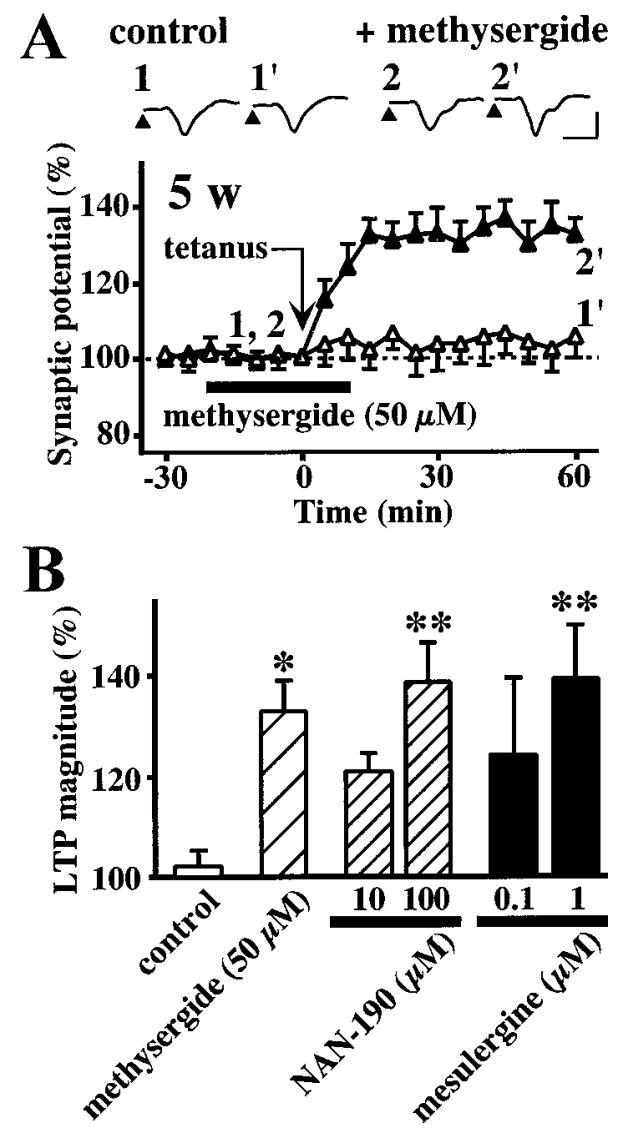

Figure 3. The effect of 5-HT receptor antagonists on the induction of LTP in the white matter-layer II/III pathway in the visual cortex slices obtained from 5-week-old rats. $A$, Time course of LTP. Tetanic stimulation was applied in the absence $(\triangle)$ or presence $(\mathbf{\Delta})$ of $50 \mu \mathrm{M}$ methysergide. Insets are sample records at the times denoted by the numbers. Calibration: vertical, $0.5 \mathrm{mV}$; horizontal, $5 \mathrm{msec}$. $B$, Effects of 5 -HT receptor antagonists, methysergide, NAN-190, and mesulergine, on the magnitude of LTP. Data are the means \pm SEM $(n=5)$. ${ }^{*} p<0.05,{ }^{* *} p<$ 0.01 versus control group; Tukey's test after ANOVA.

tent (Fig. 4A). The size or waveform of field potentials did not vary between the slices from vehicle-treated and 5,7-DHTtreated, 5-week-old rats. Tetanic stimulation failed to induce LTP in the intact slices from 5-week-old rats but did induce LTP in the slices from 5,7-DHT-treated, 5-week-old rats (Fig. 4B).

\section{DISCUSSION}

In this study, a developmental change in the induction of LTP was found in the white matter-layer II/III pathway of the visual cortex slices. Tetanic stimulation induced robust LTP in the slices from 2- or 3-week-old rats but failed to induce LTP in the slices from 5-week-old rats. The 5-HT content in the visual cortex increased during these stages. The induction of LTP in the slice from 3-week-old rats was inhibited by the addition of exogenous 5-HT, whereas the slice from 5-week-old rats exhibited LTP in the presence of the 5-HT receptor antagonist methysergide, the $5-\mathrm{HT}_{1 \mathrm{~A}}$ receptor antagonist $\mathrm{NAN}-190$, and the $5-\mathrm{HT}_{2 \mathrm{C}}$ receptor antagonist mesulergine. Furthermore, LTP was induced in the slices from 5,7-DHT-treated, 5-week-old rats. These results suggest that 5-HT increases with development and suppresses the induction of LTP in the white matter-layer II/III synapses of the rat visual cortex via $5-\mathrm{HT}_{1 \mathrm{~A}}$ and $5-\mathrm{HT}_{2 \mathrm{C}}$ receptors.

The results of our present study contrast with previous reports
A
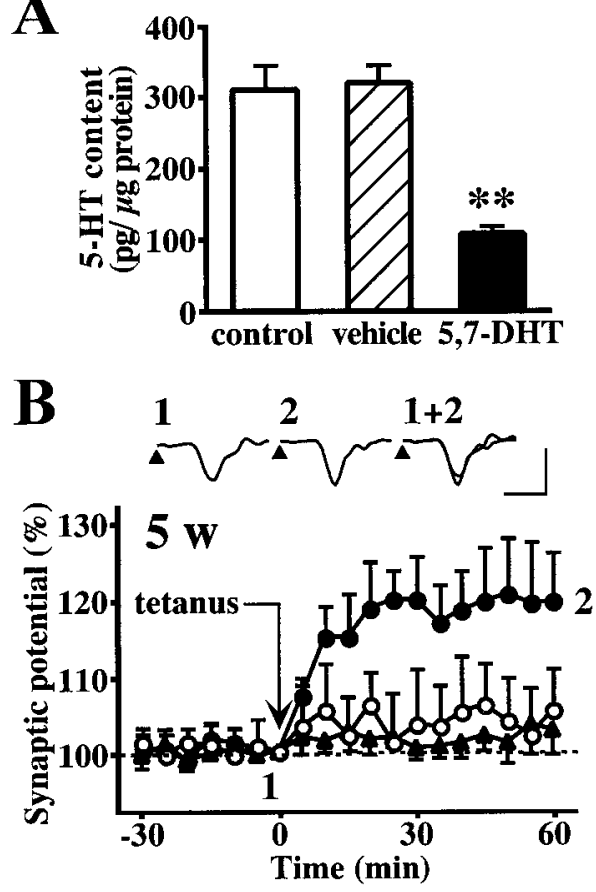

Figure 4. The effect of 5-HT depletion on the induction of LTP in the white matter-layer II/III pathway of the rat visual cortex slices obtained from 5-week-old rats. $A$, 5-HT content in the visual cortex of intact (white column), vehicle-treated (hatched column), or 5,7-DHT-treated rats (black column ). 5,7-DHT (5 $\mu \mathrm{g} / \mu \mathrm{l}, 10 \mu \mathrm{l})$ or the vehicle (saline containing $0.1 \%$ ascorbic acid, $10 \mu \mathrm{l}$ ) was injected into the lateral ventricle $6 \mathrm{~d}$ before the measurement. Data are the means $\pm \operatorname{SEM}(n=12)$. $* * p<0.01$ versus vehicle-treated group; Tukey's test after ANOVA. $B$, The induction of LTP in the visual cortex slices obtained from intact $(\bigcirc)$, vehicle-treated $(\mathbf{\Delta})$, or 5,7-DHT-treated (O) rats. Insets are sample records from a 5,7-DHT-treated rat. Calibration: vertical, $0.3 \mathrm{mV}$; horizontal, $5 \mathrm{msec}$. Data are the means $\pm \operatorname{SEM}(n=5)$.

that 5-HT enhances LTP and long-term depression in the white matter-layer IV synapses of the kitten visual cortex via $5-\mathrm{HT}_{2 \mathrm{C}}$ receptors (Kojic et al., 1997, 2000). It is possible that the role of 5-HT on synaptic plasticity is different with animal species or synaptic pathways.

The ability to exhibit LTP in the visual cortex decreased between 3 and 5 weeks of age, during which time the 5-HT content in the visual cortex increased from 100 to $300 \mathrm{pg} / \mu \mathrm{g}$ protein. In the visual cortex of 5,7-DHT-treated, 5-week-old rats, the 5 -HT content was decreased to $\sim 100 \mathrm{pg} / \mu \mathrm{g}$ protein, and LTP was induced by tetanic stimulation in this condition. Thus, 100$300 \mathrm{pg} / \mu \mathrm{g}$ protein appears to be the threshold level for endogenous 5-HT to suppress the induction of LTP.

Two questions remain, however, concerning the developmental increase of 5-HT content in the visual cortex. First, what is the origin of the 5-HT that is responsible for the regulation of LTP? The induction of LTP was facilitated by blocking the 5-HT receptor in the slices from 5-week-old rats, indicating that 5-HT functions via the 5-HT receptor at the extracellular site. Treatment with 5,7-DHT is supposed to cause the destruction of 5-HT neurons, which results in a decrease of both intracellular and extracellular 5-HT. In addition, it has been reported that 5-HT release is promoted by application of high-frequency stimulation in the dorsal raphe and suprachiasmatic nuclei of rats (O'Connor and Kruk, 1991; Bunin and Wightman, 1998). Therefore, the amount of 5-HT possibly released during tetanic stimulation may 
increase with development. Second, does the developmental increase of 5-HT content reflect a change in the distribution or density of 5-HT neurons or in the synthesis of 5-HT? Although a developmental change in the distribution and density of 5-HT neurons has been reported (Foote and Morrison, 1984; Nakazawa et al., 1992; Doli et al., 1996), there is no evidence that this innervation participates in the regulation of LTP. To answer these questions, it is necessary to identify the 5-HT neurons involved in the regulation of LTP and to measure the amount of 5-HT released from those terminals.

Kirkwood and colleagues (Kirkwood et al., 1995; Aizenman et al., 1996; Huang et al., 1999) have suggested that the developmental decline in visual cortex LTP is caused by a change in inhibition. Is the action of 5-HT on visual cortex LTP related to inhibitory neurons? $5-\mathrm{HT}_{2}$ receptors are known to be present on GABA-containing inhibitory interneurons in the cerebral cortex (Sheldon and Aghajanian, 1990). We have previously found that $5-\mathrm{HT}_{2}$ receptor agonist-induced inhibition of LTP in the layer IV-layer II/III pathway of the rat visual cortex is abolished by the presence of the $\mathrm{GABA}_{\mathrm{A}}$ receptor antagonist bicuculline, suggesting that $5-\mathrm{HT}_{2}$ receptor-mediated inhibition of visual cortex LTP is dependent on GABAergic inhibition (Edagawa et al., 2000). Furthermore, it has been reported recently that serotonin depletion alters dendritic arborization of calretinin-containing interneurons, suggesting that serotonin is a factor regulating the maturation of inhibitory interneurons (Durig and Hornung, 2000). Therefore, it is possible that 5-HT inhibits visual cortex LTP by modulating inhibitory interneurons.

Several laboratories have demonstrated previously that a developmental decrease in the ability to exhibit LTP is observed in the white matter-layer II/III pathway of the visual cortex slices obtained from 3- to 5-week-old rats (Perkins and Teyler, 1988; Kato et al., 1991; Kirkwood et al., 1995). Our present data were consistent with those previous observations, although some experimental procedures, including the strain of rats or condition of tetanic stimulation, were different. In contrast, LTP in the layer IV-layer II/III pathway did not change during postnatal development, at least from 2 to 5 weeks of age. What makes the difference in these two pathways? The addition of 5-HT suppressed the induction of LTP in the layer IV-layer II/III pathway of the visual cortex slices from 5-week-old rats as well as from 3-week-old rats (Edagawa et al., 1998a), indicating that the suppression of LTP by 5-HT can occur in this pathway regardless of age. Furthermore, 5-HT receptor antagonists had no effect on the induction of LTP in the layer IV-layer II/III pathway of the visual cortex slices from 3- to 5-week-old rats (Edagawa et al., 1998a,b, 2000), indicating that endogenous 5-HT is not involved in the induction of LTP in this pathway. It is possible that 5-HT innervation differs between the white matter-layer II/III pathway and the layer IV-layer II/III pathway and that the level of endogenous 5-HT in the latter pathway is too low to inhibit LTP. To prove this hypothesis, it is necessary to investigate a developmental change of 5-HT neurons involved in the layer IV-layer II/III pathway only.

In conclusion, we have provided evidence that endogenous 5-HT contributes to a developmental decrease in LTP in the white matter-layer II/III synapses of the rat visual cortex. 5-HT may be a factor that determines a critical period for synaptic plasticity in the rat visual cortex. In addition, 5-HT receptor antagonists or 5,7-DHT can be used as a tool in manipulating the developmental changes of visual cortex LTP. For example, testing their effects on developmental changes in visual functions will give useful clues for understanding the physiological contribution of visual cortex LTP.

\section{REFERENCES}

Aizenman CD, Kirkwood A, Bear MF (1996) A current source density analysis of evoked responses in slices of adult rat visual cortex: implications for the regulation of long-term potentiation. Cereb Cortex 6:751-758.

Artola A, Singer W (1987) Long-term potentiation and NMDA receptors in rat visual cortex. Nature 330:649-652.

Bear MF, Press WA, Connors BW (1992) Long-term potentiation in slices of kitten visual cortex and the effects of NMDA receptor blockage. J Neurophysiol 67:841-851.

Bennett-Clarke CA, Chiaia NL, Crissma RS, Rhoades RW (1991) The source of the transient serotonergic input to the developing visual and somatosensory cortices in rat. Neuroscience 43:163-183.

Bliss TVP, Lømo WT (1973) Long-lasting potentiation of synaptic transmission in the dentate area of the anesthetized rabbit following stimulation of the perforant path. J Physiol (Lond) 232:331-356.

Bunin MA, Wightman RM (1998) Quantitative evaluation of 5-hydroxytryptamine (serotonin) neuronal release and uptake: an investigation of extrasynaptic transmission. J Neurosci 18:4854-4860.

Daw NW (1994) Mechanisms of plasticity in the visual cortex. Invest Ophthalmol Vis Sci 35:4168-4179.

Doli I, Dinopoulos A, Blue ME, Parnavelas JG (1996) Regional differences in the ontogeny of the serotonergic projection to the cerebral cortex. Exp Neurol 138:1-14.

Durig J, Hornung JP (2000) Neonatal serotonin depletion affects developing and mature mouse cortical neurons. NeuroReport 11:833-837.

Dyck RH, Cynader MS (1993) Autoradiographic localization of serotonin receptor subtypes in cat visual cortex: transient regional, laminar, and columnar distributions during postnatal development. J Neurosci 13:4316-4338.

Edagawa Y, Saito H, Abe K (1998a) Serotonin inhibits the induction of long-term potentiation in rat primary visual cortex. Prog Neuropsychopharmacol Biol Psychiatry 22:983-997.

Edagawa Y, Saito H, Abe K (1998b) $5-\mathrm{HT}_{1 \mathrm{~A}}$ receptor-mediated inhibition of long-term potentiation in rat visual cortex. Eur J Pharmacol 349:221-224.

Edagawa Y, Saito H, Abe K (1999) Stimulation of the 5- $\mathrm{HT}_{1 \mathrm{~A}}$ receptor selectively suppresses NMDA receptor-mediated synaptic excitation in the rat visual cortex. Brain Res 827:225-228.

Edagawa Y, Saito H, Abe K (2000) The serotonin 5-HT 2 receptorphospholipase $\mathrm{C}$ system inhibits the induction of long-term potentiation in the rat visual cortex. Eur J Neurosci 12:1391-1396.

Fagiolini M, Pizzorusso T, Berardi N, Domenivi L, Maffei L (1994) Functional postnatal development of the rat primary visual cortex and the role of visual experience: dark rearing and monocular deprivation. Vision Res 34:709-720.

Foote SL, Morrison JH (1984) Postnatal development of laminar innervation patterns by monoaminergic fibers in monkey (Macaca fascicularis) primary visual cortex. J Neurosci 4:2667-2680.

Gu Q, Singer W (1995) Involvement of serotonin in developmental plasticity of kitten visual cortex. Eur J Neurosci 7:1146-1153.

Huang ZJ, Kirkwood A, Pizzorusso T, Porciatti V, Morales B, Bear MF, Maffei L, Tonegawa S (1999) BDNF regulates the maturation of inhibition and the critical period of plasticity in mouse visual cortex. Cell 98:739-755.

Kato N, Artola A, Singer W (1991) Developmental change in the susceptibility to long-term potentiation of neurones in rat visual cortex slices. Dev Brain Res 60:43-50.

Kirkwood A, Lee H-K, Bear MF (1995) Co-regulation of long-term potentiation and experience-dependent synaptic plasticity in visual cortex by age and experience. Nature 375:328-331.

Koh T, Nakazawa M, Kani K, Maeda T (1991) Investigations of origins of serotonergic projection to developing rat visual cortex: a combined retrograde tracing and immunohistochemical study. Brain Res Bull 27:675-684.

Kojic L, Gu Q, Douglas RM, Cynader MS (1997) Serotonin facilitates synaptic plasticity in kitten visual cortex: an in vitro study. Dev Brain Res 101:299-304.

Kojic L, Dyck RH, Gu Q, Douglas RM, Matsubara J, Cynader MS (2000) Columnar distribution of serotonin-dependent plasticity within kitten striate cortex. Proc Natl Acad Sci USA 97:1841-1844.

Komatsu Y, Toyama K, Maeda J, Sakaguchi H (1981) Long-term potentiation investigated in a slice preparation of striate cortex of young kittens. Neurosci Lett 26:269-274.

Lee KS (1982) Sustained enhancement of evoked potentials following brief, high-frequency stimulation of the cerebral cortex in vitro. Brain Res 239:617-623.

Nakazawa M, Koh T, Kani K, Maeda T (1992) Transient patterns of 
serotonergic innervation in the rat visual cortex: normal development and effect of neonatal enucleation. Dev Brain Res 66:77-90.

O'Connor JJ, Kruk ZL (1991) Frequency dependence of 5-HT autoreceptor function in rat dorsal raphe and suprachiasmatic nuclei studied using fast cyclic voltammetry. Brain Res 568:123-130.

Papadopoulos GC, Parnavelas JG, Buijs RM (1987) Light and electron microscopic immunocytochemical analysis of the serotonin innervation of the rat visual cortex. J Neurocytol 16:883-892.

Perkins IVAT, Teyler TJ (1988) A critical period for long-term potentiation in the developing rat visual cortex. Brain Res 439:222-229.

Rakic P, Lidow MS (1995) Distribution and density of monoamine receptors in the primate visual cortex devoid of retinal input from early embryonic stages. J Neurosci 15:2561-2574.
Rauschecker JP (1991) Mechanisms of visual plasticity: Hebb synapses, NMDA receptors, and beyond. Physiol Rev 71:587-615.

Sheldon PW, Aghajanian GK (1990) Serotonin (5-HT) induces IPSPs in pyramidal layer cells of rat piriform cortex: evidence for the involvement of a 5- $\mathrm{HT}_{2}$-activated interneuron. Brain Res 506:62-69.

Smith BH, Sweet WH (1978) Monoaminergic regulation of central nervous system function: II. Serotonergic systems. Neurosurgery 3:257-272.

Wiesel TN, Hubel DH (1963) Single-cell responses in striate cortex of kittens deprived of vision in one eye. J Neurophysiol 26:1003-1017.

Wright DE, Seroogy KB, Lundgren KH, Davis BM, Jennes L (1995) Comparative localization of serotonin $_{1 \mathrm{~A}}, \mathrm{CC}_{\mathrm{C}}$ and ${ }_{2}$ receptor subtype mRNAs in rat brain. J Comp Neurol 351:357-373. 